This is the penultimate version of a paper published in Synthese. The final publication is available at springerlink.com. Please cite the final, published version.

\title{
Social Norms and Unthinkable Options
}

\begin{abstract}
We sometimes violate social norms in order to express our views and to trigger public debates. Many extant accounts of social norms don't give us any insight into this phenomenon. Drawing on Cristina Bicchieri's work, I am putting forward an empirical hypothesis that helps us to understand such norm violations. The hypothesis says, roughly, that we often adhere to norms because we are systematically blind to norm-violating options. I argue that this hypothesis is independently plausible and has interesting consequences. It implies, e.g., that some experimental paradigms for investigating social norms have hitherto unnoticed shortcomings.
\end{abstract}

Institutionalized norms constrain people's behavior by making some lines of action unthinkable.

(Newman 2008, p. 103)

\section{Introduction}

There is a debate about why we adhere to social norms as much as we do. Some authors claim that norm compliance is motivated by self-interest (Binmore 2007, p. 9, 2010); others think that compliance with social norms can only be explained by a special kind of motivation, sometimes called "social preference” (Bicchieri 2006, p. 52; Camerer and Fehr 2004). Some theorists focus on the role of external sanctions, like punishment, in the 
motivation of norm compliance (Axelrod 1986); others think that internalized sanctions, like feelings of guilt and shame, are more important (Elster 2009).

The converse question is raised much more rarely: When we disobey social norms, why do we do it? The explanations for norm adherence just cited suggest an answer: sometimes we violate norms in order to maximize our personal payoff, we don't care about the payoffs of others, and neither the external nor the internal sanctions are sufficient to deter us. While such scenarios are lamentably familiar, there are norm violations that don't fit this description. As Paternotte and Grose (2013, p. 581) have pointed out:

To not respect a norm may signal one’s disregard for group traditions [...]. I can follow a norm (or not) because I want to see myself as a norm follower or as a maverick. [...T]he very fact that a behavioural rule is perceived as a norm may influence the way people comply with it [...].

In fact, norm violations can have a social and expressive function. They can be acts of political and cultural activism and a way of expressing one's views and attitudes. Let's call such norm violations “social-expressive norm violations.”

In this paper, I shall argue, first, that many accounts of social norms (when interpreted realistically) have difficulties explaining social-expressive norm violations and, second, that we can explain such norm violations if we focus on cognitive (rather than motivational) mechanisms that underlie some cases of norm adherence. For the second claim I will draw on Cristina Bicchieri’s work on the role of scripts and schemata in norm adherence. In particular, I put forward and lay the conceptual groundwork for the hypothesis that norm adherence is sometimes the result of cognitive mechanisms that 
exclude norm-violating options from practical deliberation. ${ }^{1}$ I call such mechanisms “Option Limiting Mechanisms” (OLMs) and the hypothesis just mentioned the "OLM Hypothesis.” If the OLM Hypothesis is true, it has important consequences. For one, it means that accounts of social norms should not focus exclusively on motivation; cognition is more important than is sometimes assumed. Moreover, if the OLM Hypothesis is correct, many experimental paradigms that are used to investigate social norms have unrecognized limitations because they interfere with OLMs.

The paper is structured as follows: In Section 2, I sketch some extant accounts of social norms. I go on, in Section 3, to argue that these accounts have difficulties explaining social-expressive norm violations (under a realistic interpretation). In Section 4, I introduce the OLM Hypothesis and say why it is plausible. I then explain, in Section 5, how the OLM Hypothesis can account for social-expressive norm violations. In Section 6, I point out some interesting consequences of the OLM hypothesis, and Section 7 considers some potential objections.

\section{Some Extant Accounts of Social Norms}

In this section, I sketch some prominent accounts of social norms and why people comply with them. In the next section, I will raise a problem for these accounts.

Much of the recent debate about social norms focuses on the question what motivates people to comply with social norms. Some game theorists think that compliance with

\footnotetext{
${ }^{1}$ Hence the title of this paper. Note that my use of "unthinkable" in the title differs from Frankfurt's (1988) use of the term. For Frankfurt, an action is unthinkable if the agent cannot bring herself to do it. For me, an option is unthinkable if there is a mechanism that excludes it from deliberation. I agree with Frankfurt, however, that facts about what is unthinkable partly constitute the practical and social identities of agents.
} 
social norms "mostly results in our coordinating on efficient equilibria in the real-life games that we play every day with those around us” (Binmore 2007, p. 9). This might be taken to suggest that narrowly conceived self-interest is typically enough to motivate norm adherence. Contrary to this idea, some authors regard it as essential to norms that normgoverned behavior differs from behavior motivated solely by self-interest (McAdams and Rasmusen 2007, p. 1575). Social norms are, e.g., often distinguished from conventions, i.e. social phenomena that allow agents to solve coordination problems (see Bicchieri 2006, pp. 34-42). Similarly, Jon Elster thinks that a special kind of motivation is at work in norm adherence: norms are "sustained by the internalized emotion of shame" (Elster 1999, p. 146; see also 2009, pp. 196-199, 1989, p. 113). ${ }^{2}$ Cristina Bicchieri (2006, p. 11) is more specific about the structure of the relevant motivation. On her view, it is a conditional preference: ${ }^{3}$ a behavioral rule is a social norm in a population if enough people know the rule and prefer to conform to it on the condition that enough others also conform and expect others to conform.

All these accounts involve a view about what normally motivates people to adhere to social norms. It is, thus, natural to think that what explains norm violations must be something that undercuts, counteracts, or interferes with this motivation. Perhaps the agent thinks, e.g., that she won't be too ashamed of violating the norm (on Elster's view), or she believes that most people violate the rule (on Bicchieri's view), or she realizes that she is

\footnotetext{
${ }^{2}$ Some distinctions that are worth mentioning are irrelevant for my current purposes. Elster and Bicchieri, e.g., distinguish social norms from legal norms by pointing out that legal norms are codified and enforced by people who have a special duty to do so (see Elster 2009, p. 197; Bicchieri 2006, p. 8). It is also common to distinguish social norms from moral norms. Elster, e.g., holds that moral norms are sustained by feelings of guilt whereas social norms are sustained by feelings of shame (Elster 2009, p. 196).

${ }^{3}$ A special feature of Bicchieri's concept of a social norm is that it allows for so-called "pluralistic ignorance," i.e., the possibility that a social norm for doing $A$ exists while the majority (or even all) of the members of the population in which the norm exists do not disapprove of not doing $A$ (but erroneously think that a sufficiently large subset of the population does disapprove of not doing A) (Bicchieri 2006, p. 14).
} 
playing a game where norm adherence does not maximize her payoff (on Binmore’s view), etc.

I hasten to add that the authors I have cited are not committed to these views. After all, some proponents of extant accounts don't see themselves as making claims about what happens in people's minds when they are following norms (see Paternotte and Grose 2013). Rather, they see themselves as providing a rational reconstruction of behavior (Bicchieri 2006) or an evolutionary explanation (Binmore 2010). I am interested, however, in an explanation of norm adherence and norm violations in terms of what goes on in the subjects' minds. So let's begin by interpreting the preferences and beliefs that these accounts posit in a psychologically realistic way. And let's see what we can say, on such a realistic interpretation, about social-expressive norm violations.

\section{Social-Expressive Norm Violations}

There are norm violations that are not performed because of the (narrowly conceived) advantages that they bring about for the agent. Sometimes people violate norms in order to create a public debate about norms (Benski 2005). ${ }^{4}$ They want to "make a statement," to express their views, and ultimately they want to change the society in which they live. Especially if many people follow a norm uncritically and thoughtlessly, violating a norm in

\footnotetext{
${ }^{4}$ I don't think that Benski's example (a case of political activism in Israel) should be explained in terms of the OLM hypothesis I shall present below. However, it illustrates the use of what she calls "breaching events" by social movements. OLMs are one mechanism among others that can be exploited in such "breaching events." Compare also Judith Butler's (1990) discussion of drag. The other side of the same coin is, I think, that OLMs can underlie structural explanations (see Haslanger 2015).
} 
public can be an effective way to shake up society. What do the accounts sketched in the previous section have to say about such social-expressive norm violations? ${ }^{5}$

Let's consider an example: When young males first began to wear long hair in the 1960s, there existed (I take it) a social norm against this. ${ }^{6}$ Why did these young people violate the norm? Was it self-interest that motivated these people? Did they violate the norm, e.g., because they found it aesthetically pleasing to wear long hair? Because they did not want to pay for a haircut? Maybe, but why were these advantages not outweighed by the many problems these people encountered (e.g. problems with finding a job, etc.)? The obvious answer is that these people wanted to "make a statement," they wanted to trigger a public debate about the values and social norms of their society.

It is easy for a game-theoretic account to explain why someone, e.g., defects in a prisoner's dilemma and, thereby, violates a social norm: The subject maximizes her payoff — or alternatively her utility (and her utility-function does not assign a high enough utility to obeying the norm). ${ }^{7}$ But in the case of the hippies' long hair the individual's payoff (i.e. aesthetic pleasure, savings because of fewer visits to the hairdresser, etc.) does not seem to be the crucial factor in a good explanation. Someone might reply that what really explains why they were wearing long hair was their desire to be accepted by their friends. ${ }^{8}$ Maybe this is true for a lot of cases, but it does not explain why wearing long hair was required for

\footnotetext{
${ }^{5}$ Paternotte and Grose (2013, pp. 581-584) have pointed out a related problem with traditional accounts of social norms, e.g., in the passage quoted above. However, Paternotte and Grose are not interested in the social effects that violations of norms as such might have.

${ }^{6}$ Notice that this rule was a genuine norm and not a mere convention. For people expected men to wear short hair, i.e., what Bicchieri calls "normative expectations" were present in this case. The same holds for the example of the generic pronoun below.

${ }^{7}$ On Bicchieri's account this would mean that the parameter $k_{i}$ in the agent's utility function - which "represents a player's sensitivity to the relevant norm" (Bicchieri 2006, p. 52) - is too small to keep the agent from defecting.

${ }^{8}$ Smith, Thomas and McGarty (2014) have offered an account of such phenomena in new social movements. They argue that agreement on new social norms can lead to new social identities.
} 
being accepted or how the trend began in the first place. Some people must have started the whole thing. Why did those people wear long hair and, thereby, violate the social norm?

To this a game-theorist might reply: "Of course, the hippies wore long hair because they wanted to create a public debate about social norms etc. But that just means that these people had a preference for the existence of certain debates.” This is a perfectly good answer, but it does not tell us why the violation of social norms should lead to a public debate about these norms. If game-theoretic models can explain how social norms influence our actions, they should have something to say about how and why the violation of social norms can be used to “make statements” and trigger debates.

According to Bicchieri’s account, one can undermine a social norm by undermining the expectation of a sufficiently large subset of people in the relevant group or population that a sufficiently large subset of the people in the relevant group or population will act in accordance with the norm (Bicchieri 2006, p. 11). So, Bicchieri’s account can explain why someone who wants to undermine a social norm would want to get a lot of people to violate the norm in public. Undermining a social norm by changing the expectations of people is not, however, the same as triggering a public debate. Changing the expectations of people is, on Bicchieri's account, a matter of changing people’s beliefs about whether a norm is in force. But the hippies, I take it, did not want to persuade people that certain norms were not in force; they wanted to convince people that the existing norms should not be in force. According to Bicchieri's account, wearing long hair should make people believe that there really does not exist any norm against wearing long hair. I think quite 
the contrary is true: After the hippies started to wear long hair, people became more, rather than less, aware of the fact that there was a norm against it.

According to Elster's view, we should expect that the primary emotional reaction of people to hippies wearing long hair was contempt and that the primary emotional reaction to this contempt on the side of the hippies was a feeling of shame (Elster 2009, p. 197). This doesn't seem right, at least for the emotional reaction of the hippies. Regarding the reaction of the other people, the question arises: Why should the hippies have wanted to produce contempt in them? Given that the hippies grew their hair long in order to trigger a public debate and to "make a statement," how can this be done by producing contempt? Of course, one can tell a story about how producing contempt might lead to a social strain, which in turn might lead to a public debate. But that story is in no way entailed by Elster's account.

Notice that the hippies' motivation that trumped their potential motivation to adhere to the norm was not independent of that very norm. They wouldn't have felt so strongly about their hair if there hadn’t been a norm against wearing long hair. How can norms play this role? None of the accounts we have looked at gives us much insight into why social norms lend themselves to social-expressive norm violations.

Let's consider another example: the use of the generic female pronoun. Traditionally there was a norm, to use "he" as the generic pronoun, as in "When someone asks you, tell him." With the rise of feminism, some people started to use "she" as a generic pronoun. Such norm violations were not only intended to "put things right.” At least initially, they were also meant to trigger a debate about gender inequality. By using the female generic pronoun you could express a view and take a side in the struggle for women's liberation. 
Here again it is implausible that those who began using "she” as a generic pronoun did so (solely) because of the practical advantages, ${ }^{9}$ the desire to generate contempt in their audience, or a plan to undermine the empirical expectations that others follow the norm. They did it, at least in part, in order to put an alternative on the table. And putting an alternative on the table expresses a view and can trigger a debate about the violated norm.

As with the hippies’ long hair, the motivation for violating the norm is not independent of the existence of the norm. What is going on in social-expressive norm violations? The realistic interpretations of the accounts mentioned in the previous section don't give us much insight into such cases. It is hard to see, on such accounts, why something being a norm can motivate you to violate that very norm.

\section{The OLM Hypothesis}

In order to get a better understanding of social-expressive norm violations, we should reject the realistic interpretation of the beliefs and preferences that figure in the accounts mentioned in Section 2. It is worth taking a closer look at the cognitive mechanisms that can lead to norm adherence. Drawing on Cristina Bicchieri’s (2006, pp. 81-99) work on the role of scripts and schemata in norm adherence, I want to suggest an empirical hypothesis about how norms can sometimes influence behavior.

\section{Option Limiting Mechanism (OLM) Hypothesis}

Some cases of norm adherence are explained by

9 There actually are practical advantages if one uses both pronouns as generic pronouns: certain ambiguities can be avoided. The sentence "For everyone who thinks that he is better than everyone else, there is someone who is better and he loves him," e.g., is ambiguous in a way that the sentence "For everyone who thinks that he is better than everyone else, there is someone who is better and she loves him” is not. 
OLM-H1 cognitive mechanisms (involving scripts and schemata) that eliminate norm-violating options from the set of options an agent considers in practical deliberation,

OLM-H2 where the presence of these mechanisms in the agent is explained by the existence of the social norm whose violations are filtered out.

The idea is this: options become available to an agent in deliberation by a subpersonal, two-stage process. The result of the first stage is a set of options that is not yet filtered with respect to norm-conformity. An OLM operates on the result of this first stage and filters out the norm-violating options. The result of this second stage then becomes available for deliberation. Both stages of this process are subpersonal, automatic processes. ${ }^{10}$

Before we proceed, six points of clarification are in order: First, the norms for which it is most plausible that they are sustained by OLMs are what we may call "internalized norms.” By this I mean norms that have become a matter of course for us; we rarely think about them, and acting in accordance with them has become second nature to us. These are typically norms that also structure the way we perceive our social environment and that can easily trigger emotions in us. ${ }^{11}$ Many norms concerning how to eat, dress, interact and talk are internalized in this sense. The norms I have in mind in putting forward the OLM Hypothesis are of this kind. After all, it seems too easy to become aware of the option of

\footnotetext{
${ }^{10}$ They probably belong to what is sometimes called "System 1" (Kahneman 2011).

${ }^{11}$ The OLM Hypothesis can contribute to an understanding of what it means that such norms structure the perception of our social environment. After all, OLMs change the options we are aware of, and these options typically involve particular interactions with our social surroundings.
} 
violating norms that are not internalized (although it is ultimately an empirical question which norms, if any, are adhered to because of OLMs).

Second, I want to block a worry about computational plausibility: an OLM does not need to go through all the norm-violating options. An OLM operates on the results of the first stage of the two-stage process just sketched and is, hence, not computationally implausible.

Notice, thirdly, that the OLM Hypothesis is not the trivial claim that we sometimes follow norms because we don't consider the option of violating them. Rather, the idea is that this happens in a systematic way that is explained by the existence of the norm itself. The OLM Hypothesis says neither that whenever you don't do something because you don't consider doing it you are adhering to a norm against doing it, nor that whenever you follow a norm you don't consider the option of violating it. ${ }^{12}$ The OLM Hypothesis is an empirical hypothesis about one way among others in which norms influence behavior.

Fourth, it is worth pointing out that subpersonal mechanisms that limit the options that an agent considers probably also play an important role in domains that have nothing to do with social norms (more on this below). The OLMs that I am interested in are, however, specific to social norms because they filter out norm-violating options and their existence depends on social norms.

Fifth, I want to stress that my aim here is to lay the conceptual groundwork for the OLM Hypothesis. Establishing the truth of the OLM Hypothesis requires empirical

\footnotetext{
${ }^{12}$ After all, there are cases in which it is utterly implausible to think that people comply with a norm because they do not consider violating it. Practices like female genital cutting persist in some communities in Africa even after explicit efforts to change the relevant norms have been made and alternatives have been pointed out (see Bicchieri and Mercier 2014). My hypothesis is not meant to apply to such cases. It is implausible to assume that the same mechanism underlies all cases of norm compliance (Andrighetto et al. 2014), and I am making a proposal about one such mechanism.
} 
research; this goes beyond the theoretical philosophical work I can do here. For now, all I want to claim is that the OLM Hypothesis is a coherent, interesting and plausible hypothesis that has explanatory power.

Finally, I want to be clear that the OLM Hypothesis is not an account of social norms; it is not a rival to the accounts sketched in Section 2. It is a claim about mechanisms that sometimes underlie norm adherence. Nevertheless, a realistic interpretation of the accounts sketched in Section 2 is incompatible with the OLM Hypothesis. After all, the OLM Hypothesis does not even mention preferences, and the accounts from Section 2 realistically interpreted — explain norm adherence in terms of preferences.

In the next two subsections, I will explain why the OLM Hypothesis is plausible. I will discuss the two parts of the hypothesis, i.e. OLM-H1 and OLM-H2, in subsections 4.1 and 4.2 respectively. In subsection 4.3, I further clarify the OLM Hypothesis by suggesting ways in which it can be tested empirically. In Section 5, I will then look at how the OLM Hypothesis helps us to understand social-expressive norm violations.

\subsection{Limiting the Space of Options}

Let's think about OLM-H1. The idea that there are cognitive mechanisms or states that exclude options from deliberation is not new. In the philosophy of action, e.g., Michael Bratman (1987, p. 33) has argued that prior intentions and plans "narrow the scope of deliberation to a limited set of options" by providing "filter[s] of admissibility for options." According to OLM-H1, a similar idea can be applied in some cases of norm adherence. ${ }^{13}$

\footnotetext{
13 Perhaps similar ideas can also be found in work on bounded rationality. There are, however, also differences between OLMs and mechanisms that may underlie bounded rationality, such as satisficing (Simon 1956; Gigerenzer 2010; Gigerenzer and Brighton 2009). Both, OLMs and satisficing, reduce
} 
Cristina Bicchieri (2006) has argued that the influence of norms on behavior is mediated by scripts. In particular, she holds that which norm influences an agent's behavior depends on how the agent interprets the situation, which in turn depends on what scripts are activated. I agree, and I think that one way in which this happens is that script activation leads to the elimination of norm-violating options from deliberation. Similar phenomena have been described in the literature on schema-based decision-making (Marshall and Seel 2012). It is well-known, e.g., that in many cases of decision-making people with the relevant experience consider only a very limited number of options and these options are typically "good” ones (Klein 1995; Ross et al. 2004). ${ }^{14}$ Lipshitz and Ben Shaul (1997) have argued that this limitation of options is the result of the activation of schemata that leads to the formation of mental models, which in turn triggers the retrieval of a specific repertoire of available options from memory. So there is evidence that schemata and scripts can influence the set of options an agent considers. If Bicchieri is right and norm adherence is mediated by script activation, it is plausible that such limitations of options can sometimes explain norm compliance. ${ }^{15}$ An example from Garfinkel (1967) may illustrate this possibility. Garfinkel asked students to bargain for standard priced merchandise. There is a social norm against such attempts to bargain. This comes out in the fact that many students could not bring themselves to do it or felt uncomfortable. However, "many students reported that they had learned to their 'surprise'

computational complexity compared to cognitive mechanisms that compute, e.g., which of all possible options maximizes utility. On the other hand, OLMs reduce the number of options in the search space, whereas satisficing and most heuristics described within the bounded rationality framework introduce new rules for when to stop searching and for how to decide between the options in the search space.

${ }^{14}$ The examples that are most often used are the decisions of firefighters, military commanders, and chess players.

${ }^{15}$ One might further hypothesize that a neural mechanism like the one postulated by Antonio Damasio's Somatic Marker Hypothesis is responsible for this exclusion of options (see Bechara 2011; Bechara and Damasio 2005). 
that one could bargain in standard priced settings with some realistic chance of an advantageous outcome, and planned to do so in the future” (Garfinkel 1967, p. 69). It seems plausible that these students did not consider the option of bargaining in standard price settings before participating in the study; the activation of a schema for standard price settings excluded this option from deliberation. ${ }^{16}$ Once they were aware of the option, however, they couldn't see any reason for not choosing it. Given OLM-H1, that is what we should expect.

In light of this converging research in psychology, sociology and philosophy, it is plausible that when an internalized norm governs behavior in a certain kind of situation, the script that is activated by such situations can lead to the elimination of all normviolating options. I.e., the combination of the mechanisms underlying schema activation, mental model formation and thereby influenced memory retrieval constitutes an OLM. Thus, the agent adheres to the norm because she does not consider violating it. Whether an OLM is triggered depends on how the agent interprets the situation, i.e. on what scripts are activated. ${ }^{17}$ Thus, the cited research lends plausibility to OLM-H1.

\subsection{Putting OLMs in Place}

What about OLM-H2, i.e. the claim that norms can explain why OLMs are present in agents? This point can be illustrated by looking at the upbringing of children. The second part of the OLM Hypothesis implies that when we, e.g., teach our kids to eat using

\footnotetext{
${ }^{16}$ Notice that I do not claim that the norm violations in Garfinkel's study were social-expressive norm violations. Not all violations of OLM-sustained norms are social-expressive norm violations.

${ }^{17}$ Given that schema theory has long been criticized for being too vague (e.g. Beers 1987; Alba and Hasher 1983), it is desirable to specify — as I just did — the precise mechanism by which script activation leads to norm compliance.
} 
silverware, to greet guests, or to say "please” when asking for something, this typically leads to an OLM in the kids.

How can an upbringing in the context of social norms lead to OLMs? We know from the work of Michael Tomasello and his colleagues that children have a tendency to spontaneously follow (and even create) norms and to interpret situations normatively (Göckeritz et al. 2014; Schmidt et al. 2012, 2011; Rossano et al. 2011; Wyman et al. 2009). Moreover, young children tend to use language that objectifies norms, i.e. language that presents the norm as an "unalterable fact,” e.g., "It works like this” rather than "You must do it like this” (Köymen et al. 2014). Thus, children seem to conceive of norms as limits of their "space of agency" that are simply "out there.”

Given this characteristically human motivation to comply with norms and potential sanctioning by adults, deliberating about the option of violating a given norm is cognitively costly and futile for children. And it is costly and futile because a norm against these options exists. The development of an OLM helps children to cut down on cognitive costs while focusing on the "good options." Once children adhere to the norm because of an OLM, this behavioral pattern tends to persist even without any sanctions because people who have acquired OLMs as children don't consider the option of violating the norm. This is in line with results from psychology showing that norm-compliance tends to persist even outside the circumstances that initially led to it. As Sherif puts it, norms tend to "outlive their usefulness” (Sherif 1936, p. 198; see also Bicchieri 1990).

These considerations lend plausibility to OLM-H2. Not only can OLMs explain (some cases of) norm adherence, but it is plausible that norms can explain OLMs. 


\subsection{Empirical Testability of the OLM Hypothesis}

It can seem that the OLM Hypothesis is banal: of course, we don't always consider every possible option, and this can explain why we are not choosing the options we are not considering. Does the empirical content of the OLM Hypothesis go beyond this obvious fact? Although I here merely want to lay the theoretical groundwork for the OLM Hypothesis and I'm not trying to establish its truth, the best way to bring out the empirical content of the hypothesis is to consider how it might be tested. I think we should begin by testing the two parts of the OLM Hypothesis separately.

First, we should test whether people sometimes comply with norms because they systematically fail to consider violating them (i.e. OLM-H1). One way to approach this task is to ask: How can we tell the difference between an option that is unavailable in deliberation due to an OLM and an option that is systematically much worse than other options? There are two important differences. First, options excluded by OLMs are more likely to be chosen if they are made salient to the agent. Second, it is more difficult to alert a subject to an option that is excluded by an OLM than to alert her to an option that is merely much worse than the alternatives. How could we test these predictions?

One way of testing these predictions would be to take two different situations in which subjects are typically not aware of having a certain option and the option has a clear advantage over other options. In one situation there is a norm against choosing the relevant option and the norm is plausibly sustained by OLMs; ${ }^{18}$ in the other situation there

\footnotetext{
${ }^{18}$ As already intimated, OLMs are probably more important in cases of internalized norms than in other cases. So the OLM Hypothesis should be primarily investigated with respect to such norms.
} 
is no such norm. ${ }^{19}$ We manipulate the salience of the ignored option in both cases. If OLM-H1 is correct, two things should happen. First, as subjects become aware of the norm-violating option (due to its increased salience), norm compliance should go down. After all, the salience of the option should undermine the OLM. Second, it should be more difficult to make people aware of the ignored option in the case where there is a norm against choosing the option than in the other case. This reflects the fact that there is a difference between being unaware of an option because of an OLM and being unaware of an option where this is not the result of an OLM.

The second part of the hypothesis, i.e. that norms can lead to OLMs (OLM-H2), is harder to test in the lab. We would need to create "artificial” social norms and compare groups in which such a norm was created to other groups and check whether their awareness of the relevant options differ. This might be difficult for at least two reasons: First, it might take time for a social norm to lead to an OLM. Second, it is unclear whether we can create genuine social norms of the right kind (i.e. internalized norms that are plausibly sustained by OLMs) in the lab. ${ }^{20}$ So we will probably have to supplement such experiments with research in the field. We could investigate, e.g., how the options that children deliberate about change as they start to comply with social norms. If OLM-H2 is correct, their awareness of norm-violating options should decrease.

These are, of course, very rough sketches of possible empirical studies. I have left out many details. For example, we would need to control for possible normative interpretations of making an option salient and motivational factors that contribute to norm

\footnotetext{
19 The second kind of situation should be unfamiliar to the agent in order to rule out that a mechanism like an OLM (that is not norm related) is also operative in this condition.

20 Göckeritz et al. (2014) argue that norms can spontaneously develop in the lab. One might doubt, however, that such norms can be internalized in the lab. And it seems plausible that only internalized norms can be sustained by OLMs.
} 
compliance. Nevertheless, these sketches show that the OLM Hypothesis has testable empirical content. And given that my aim here is to provide a novel theoretical perspective, this suffices for my present purposes.

This relates to a prominent topic in the psychological literature: the salience of norms. We know that whether people behave in accordance with a social norm depends on the salience of the norm (for an overview over some of the literature see Bicchieri 2006, pp. 63-70). Cialdini et al. found, e.g., that subjects were significantly more likely to litter in an already littered environment in which they observed other people littering than in a clean environment or when they did not observe other people littering (Cialdini et al. 1991). My hypothesis suggests a novel interpretation of these data. In cases where OLMs are relevant, it is not so much the salience of a norm that influences behavior but rather the salience of the possibility of violating the norm. If this possibility is made salient, that undermines the OLM. If this interpretation of the data can be corroborated, this would lend empirical support to the OLM Hypothesis.

\section{OLMs and Social-Expressive Norm Violations}

How can the OLM Hypothesis help us to understand social-expressive norm violations? If the fact that a group of people comply with a norm is explained by a socially shared OLM, these people comply with the norm because they don't consider the option of violating it. If the norm is publically and saliently violated, however, it is difficult to "ignore" the option of violating the norm. After all, humans can learn by observing others (Bandura and Walters 1963). Hence, publically violating a norm that is sustained by OLMs will 
force everyone to consider the option of violating the norm. The norm becomes visible for everyone. Once everyone is aware of the norm and the option of violating it, the norm can be thematized and questioned. ${ }^{21}$ The mere act of making it obvious that there are alternatives to norm adherence can put pressure on advocates of the norm to provide reasons for having the norm around. Thus, social-expressive norm violations make sense if the norm violated is typically followed because of an OLM. I am not claiming that this is the only role social-expressive norm violations can play, but I think it is plausible that they often do play the role just described.

Let's look at our examples from Section 3 again. According to my view, hippies grew their hair long in order to make a statement of roughly the following kind: "You, nonhippies, do not realize how restricted you are by your social norms. You do not realize that there are all these other ways one might dress; just as you do not realize that there are all these other ways one might live. I will make you see all these other ways of doing things.” By making people aware of different ways of living, the hippies "forced" everyone to think about these options and, if people wanted to stick to their norms, to articulate reasons against choosing these options. The social-expressive norm violations of the hippies enlarged the menu of options for everyone, and this made it possible to have a debate about all these options and the norms against some of them.

Let's turn to the example of the generic pronoun. According to the OLM hypothesis, the way this works is this: people who internalized sexist norms of language-use did not even consider the option of using "she" as a generic pronoun. The question did not arise for them. When people started to use "she" in this way, it became obvious that this option

\footnotetext{
${ }^{21}$ The feeling of surprise that results from realizing that there are more options than one had thought might be important for mobilization in new social movements (Scheff 2006; Jasper 2011).
} 
exists (and many more, as the many proposals that are on the table today show). One reason why this is a particularly effective way to trigger a debate is that it shows how widespread the unconscious influence of norms of gender inequality is. And because people did not consider the alternative, they typically were not prepared to give reasons for preferring the old way of doing things.

An opponent might say that such phenomena can be explained by saying that although people were aware of the norm-violating options, they were not aware that some people prefer not to follow the norm and can be motivated to violate it. I find this implausible for the following reason: If people considered violating the norm, they must have preferred to follow it. Movements like the hippies and feminism, however, often made many people first realize that they do not prefer to follow the existing norms. Creating the right kind of “consciousness” was (and is) on the agenda of such movements, and social-expressive norm violations are an important part of this. Moreover, if such social-expressive norm violations did not focus on options that people were not previously aware of, they would probably be less effective. After all, people would probably be prepared to give (nonridiculous) reasons for why one should follow the norm. Furthermore, there are cases in which it seems implausible that people could think about the norm but not realize that many others would prefer not to follow it, e.g., norms of gender inequality.

\section{Consequences of the OLM Hypothesis}

I want to point out four interesting consequences of the OLM Hypothesis. 
(i) If the OLM Hypothesis is correct, cognitive mechanisms play a larger role in norm adherence than is sometimes assumed. The OLM Hypothesis can explain some cases of norm adherence in a purely cognitive way; no preferences or motivations are mentioned in the explanation for why the agent complies with the norm. Of course, creating and sustaining OLMs depends on motivational factors, and motivation may play a crucial role in many cases of norm compliance. (And especially the fact that people typically disapprove of norm violations cannot be explained by the OLM Hypothesis.) For some cases, however, OLMs can explain why someone complies with a norm without positing any special motivation (at the time of action) to comply with the norm.

The reader might be puzzled how the OLM Hypothesis can be an elaboration of Bicchieri’s use of scripts and schemata, given that Bicchieri’s own account explains norm adherence in terms of preferences. ${ }^{22}$ Is it really possible to selectively accept only parts of Bicchieri's view? Part of the answer to this worry is that, as Bicchieri herself points out, her account in terms of preferences and utility is "not a faithful descriptive account of the real beliefs and preferences people have or of the way in which they in fact deliberate" (Bicchieri 2006, p. 3). Rather, these considerations belong to a rational reconstruction that must be distinguished from the psychological account in terms of scripts. A second part of the answer is that, while Bicchieri sees no tension between her account in terms of preferences and her account in terms of scripts, I think that the OLM Hypothesis brings out that there is at least a potential tension here. After all, it is at least not immediately obvious how you can incorporate something like the OLM Hypothesis into a "rational

\footnotetext{
22 Thanks to an anonymous referee for pressing me on this point.
} 
reconstruction” in terms of preferences, i.e., how you could come to the same predictions as the OLM Hypothesis if you work only with beliefs and preferences.

(ii) If the OLM Hypothesis is true, many experimental paradigms that are used in the game-theoretic tradition are not a good way to investigate social norms, at least in cases where OLMs are relevant — pace Camerer and Fehr (2004). For such experiments typically force subjects to choose between a few salient options. Bicchieri and Chavez (2013), e.g., explained to each Proposer in an Ultimatum Game that she has exactly three options to divide her $\$ 10: 5 / 5,8 / 2$, or let a fair coin decide between the previous two options. And we can suppose, for the sake of argument, that dividing the money unevenly violates a social norm. Thus, typical game-theoretic experiments make the option of violating social norms salient to the subjects. They thereby make it hard for subjects to deliberate in such a way that the question whether or not to violate the norm never arises. ${ }^{23}$

(iii) Most accounts of social norms have little to say about the phenomenology of acting in accordance with norms. All that John Searle, e.g., has to say on this topic is that people acting in accordance with what he calls "constitutive rules" need not have any beliefs or desires regarding these rules (Searle 1995, p. 127). Jon Elster (2009, p. 196) tells us a little bit more:

\footnotetext{
${ }^{23}$ Since I don't claim that OLMs are the only way in which social norms influence behavior, what I just said does not mean that traditional game-theoretic experiments cannot tell us anything interesting about social norms. We have learned a lot from such experiments.
} 
[T] he operation of social norms depends crucially on the agent being observed by others. The anticipation of being observed may cause her to abstain from the norm-violating behavior or to hide it carefully. Actually being observed may trigger one of the action tendencies of shame: hide, run away, or kill oneself.

Elster believes that the experience of shame is a crucial component in the mechanism sustaining social norms. However, these emotions are triggered by the violation of norms and, hence, Elster is not telling us much about the phenomenology of conforming to norms.

By contrast, the view I am suggesting has something to say about what it is like for an agent to act in accordance with an internalized norm because of an OLM: the question whether or not to obey a certain social norm does not arise for an agent influenced by an OLM. From a first-personal perspective the norm-conforming character of the agent's way of deliberating and acting is invisible. Hence, the agent does not feel forced to comply with the norm. I think this description is true to the typical phenomenology of complying with internalized social norms.

This is not a merely negative claim about the phenomenology. It implies a contrast: conforming to a norm because of an OLM differs phenomenologically from other cases of norm compliance in that it is invisible from the subject's perspective.

It may seem that other accounts can tell a similar story. For anyone who countenances unconscious mental states can draw a distinction between consciously conforming to a norm and unconsciously doing so. My response to this brings me to the fourth and final point.

(iv) According to the OLM Hypothesis, norm adherence can be explained by a subpersonal, unconscious mechanism, and the behavior can still be the result of complex, 
conscious deliberation. This result goes beyond, e.g., Bicchieri's distinction between a heuristic and a deliberational route to norm adherence (Bicchieri 2006, p. 5). For according to the OLM Hypothesis, an agent can go through tedious, explicit, conscious deliberation and still be under the influence of an OLM; the agent simply does not see the excluded options.

\section{Objections}

I now want to consider five possible objections against the view I am suggesting.

Objection (i): OLMs are a completely general phenomenon and have nothing to do with social norms. Answer: I agree that something like OLMs play important roles in domains that have nothing to do with social norms, e.g., in expert decision making (see Section 4.1 above). Moreover, there are cases of norm compliance that have nothing to do with OLMs. This does not mean, however, that OLMs never explain norm compliance, as the OLM Hypothesis says.

An analogy may help to bring this out. I sometimes follow a social norm because doing so pleases my partner. This means neither that whenever I follow a norm, I do so because it pleases my partner nor that whenever I do something because it pleases my partner, I am following a norm. Nevertheless, what explains my norm compliance in said cases is that I want to please my partner. An exactly parallel situation is common for norm compliance because of OLMs. Sometimes I follow a norm because the existence of the norm in my society has led to a mechanism that systematically excludes norm-violating options from my deliberation. This is not in conflict with the idea that I am sometimes 
able to make expert decisions because my experience has led to a mechanism that systematically excludes options that are unlikely to result in good outcomes from my deliberation. Nor does this mean that this is the only way in which I can come to follow a norm. The situation is structurally identical to the situation with the wishes of my partner.

Moreover, we should not ignore OLMs when we want to understand phenomena like social-expressive norm violations. After all, these are very special phenomena and the specific mechanisms that underlie certain cases of norm violation can make a difference here - or so I argued above. Without the OLM Hypothesis we couldn't say that socialexpressive norm violations can work by putting an option on the table that was previously systematically neglected.

Objection (ii): There is evidence that people do not follow social norms if they believe that other people do not follow them either (Bicchieri and Xiao 2009; Nolan et al. 2008). It might seem that my view is not compatible with this because OLMs exclude options unconditionally. Answer: As explained above, if someone expects that others will violate a norm (as interpreted by the OLM-triggering schema), she will no longer follow the norm because of an OLM (though she might continue to comply because of some other factor). For if the agent expects others to violate the norm, she can consider the option of violating the norm herself.

One might worry that this makes OLMs too fragile to sustain social norms. In response, I want to point out four things: First, it is plausible that OLMs typically work in tandem with motivational factors that help to sustain the OLMs. Second, there actually are norms that are hardly ever violated in public (e.g. licking one's plate after dinner); in such cases, corresponding OLMs can be sustained easily. Third, since OLMs depend on 
schemata, it is possible to observe a norm-violation without this interfering with the OLM if the norm-violation is not interpreted in terms of the OLM triggering schema. Fourth, it is actually the relative fragility of OLMs that makes social-expressive norm violations very effective in cases where a norm is mostly followed because of an OLM and not because of a particular motivation to comply with the norm.

Objection (iii): An opponent might think that my explanation of social-expressive norm violations really only works for conventions and not for genuine social norms. After all, social norms are often distinguished from conventions on the basis that acting in accordance with a convention furthers the narrowly conceived self-interest of the agent (as long as everyone else also follows the convention), while this is not so for social norms. "Conventions do not run counter to selfish motives, but social norms often do" (Bicchieri 2006, p. 44). An opponent might think that this implies that violations of norms always make someone other than the agent worse off, while this is not so for conventions. Violating norms of fairness, e.g., typically makes someone other than the agent worse off than she would otherwise be. So, the opponent continues, norm violations will not trigger a public debate. Rather, they will simply be met with accusations of selfishness. Hence, the OLM account is implausible for genuine norms. ${ }^{24}$

In response to this worry, I want to point out two problems with this objection. The first one is that the distinction between norms and conventions does not imply that violating a norm always makes someone else worse off, while going against a convention never does so. In many countries where people drive on the right side of the street it is a convention that pedestrians ceteris paribus pass each other on their left sides. This is a

\footnotetext{
${ }^{24}$ Thanks to an anonymous referee for raising this worry.
} 
typical convention in that no one could gain anything be violating the convention; it's a Nash Equilibrium. Notice, however, I not only making myself worse off by violating the convention, I also make other people worse off. After all, I bump into them. Conversely, there are norms whose violations don't hurt anyone. There once was, e.g., a genuine norm to show up to a duel if someone “requested satisfaction.” However, you didn’t make anyone worse off by not showing up to the duel. Thus, the objection rests on an implication that simply does not hold.

The opponent might grant this logical point but still hold that the OLM Hypothesis can only explain norm violations that don't make anyone worse off than she would otherwise be. However, this doesn't seem right. Here is an example: In many countries where spending some time in the military is compulsory, there is a social norm to serve one's time in the military. And we can easily imagine that, for many, violating this norm is not an option they deliberate about — and this is so because of an OLM. Spending time in the military simply seems to these people to be a natural part of their lives. It's "what one does." This creates the conditions under which pacifists might try to shake up society by publically refusing to join the military. Arguably, these pacifists make everyone else worse off because the nation will have to get by without their military service. Here the OLM account can explain norm violations that make people other than the agent worse off. In general, the OLM account can even explain social-expressive norm violations that put a particular group at a disadvantage, relative to the situation without the norm violation, if the agents think that there is a reasonable chance that many people will doubt that the group has a right to the benefits that accrue to them because of the norm. So the objection fails. Nevertheless, I acknowledge that typical agents who engage in social-expressive 
norm violations will make sure that they are not perceived as selfish. But this doesn't undermine my account.

Objection (iv): We sometimes act without deliberation out of a habit. Can habit perhaps in conjunction with motivation — do all the explanatory work that the concept of an OLM can do? Answer: Note that cases of norm compliance that are explained by OLMs can be the result of complicated deliberation. I can make intricate plans about my behavior during a job interview, e.g., without ever considering many ways in which I could violate social norms during the interview. In such cases, my behavior is neither simply habitual nor does it necessarily maximize my chances of getting the job (perhaps certain norm violations would be well-received). Maybe an opponent would reply that what is at issue is not a habit of acting a certain way but a habit of deliberating a certain way. Such a view would be very close to my own view. There are two important differences, however. First, on my view, a social norm is a crucial factor in bringing about the OLM. If the "habit" arose in some other way, this would not be a case in which the behavior is influenced by a social norm. Second, the OLM Hypothesis says that there is a mechanism that makes the subject systematically blind to norm-violating options. Thus, if the OLM Hypothesis is correct, it should be harder to alert someone to an option that is excluded from deliberation because of an OLM than to an option that merely goes against the agent's habits.

Objection (v): It might seem that OLMs cannot apply to proscriptive norms; for such norms make the option of violating the norm salient by explicitly mentioning it. Answer: Since OLMs are subpersonal, unconscious mechanisms, the subject need not be aware of any formulation of the norm that she follows because of an OLM. It may be difficult to 
create an OLM for a proscriptive norm in someone else. One way in which this might happen is that such norms are translated into constraints on attaining norm-independent goals, e.g.: you should try to reach your goals in a fair way. In this way, the upshot of the norm "Don't be unfair" can be formulated without mentioning the option of being unfair.

\section{Conclusion}

I have described cases of social-expressive norm violations, and I have argued that realistic interpretations of some prominent recent accounts of social norms don't give us much insight into such cases. If we accept the OLM Hypothesis and assume that people

sometimes adhere to norms because they are systematically blind to norm-violating options, this helps us to understand social-expressive norm violations. The OLM hypothesis is independently plausible and has some interesting consequences. In particular, it highlights the importance of cognition in norm adherence. Moreover, if the OLM Hypothesis is correct, many experimental paradigms for investigating social norms have hitherto unnoticed shortcomings. Given all this, I think that the OLM Hypothesis deserves to be taken seriously and to be investigated empirically.

\section{References}

Alba, J. W., \& Hasher, L. (1983). Is memory schematic? Psychol Bull, 93(2), 203-231. Andrighetto, G., Villatoro, D., \& Conte, R. (2014). Norm dynamics within the mind. In M. Xenitidou, \& B. Edmonds (Eds.), The complexity of social norms (pp. 141-160, Computational Social Sciences). Cham, Heidelberg: Springer. 
Axelrod, R. (1986). An evolutionary approach to norms. The American Political Science Review, 80(4), 1095-1111.

Bandura, A., \& Walters, R. H. (1963). Social learning and personality development. New York: Holt.

Bechara, A. (2011). The somatic marker framework and the neurological basis of decision making. In Richard Ebstein, S. Shamay-Tsoory, \& S. H. Chew (Eds.), From DNA to Social Cognition (pp. 157-183). Hoboken, NJ: Wiley-Blackwell.

Bechara, A., \& Damasio, A. R. (2005). The Somatic Marker Hypothesis: A Neural Theory of Economic Decision. Games and Economic Behavior, 52(2), 336-372.

Beers, T. (1987). Schema-theoretic models of reading: humanizing the machine. Reading Research Quarterly, 2, 369-377.

Benski, T. (2005). Breaching events and the emotional reactions of the public: Women in Black in Israel. In H. Flam, \& D. King (Eds.), Emotions and social movements (pp. 57-78). London: Routledge.

Bicchieri, C. (1990). Norms of cooperation. Ethics, 100, 838-861.

Bicchieri, C. (2006). The grammar of society: the nature and dynamics of social norms. New York: Cambridge University Press.

Bicchieri, C., \& Chavez, A. K. (2013). Norm manipulation, norm evasion: experimental evidence. Economics and Philosophy, 29(2), 175-198.

Bicchieri, C., \& Mercier, H. (2014). Norms and beliefs: how change occurs. In M. Xenitidou, \& B. Edmonds (Eds.), The Complexity of Social Norms (pp. 37-54, Computational Social Sciences). Cham, Heidelberg: Springer.

Bicchieri, C., \& Xiao, E. (2009). Do the right thing: but only if others do so. Journal of Behavioral Decision Making, 22(2), 191-208, doi:10.1002/bdm.621.

Binmore, K. (2007). Does game theory work?: the bargaining challenge (Economic learning and social evolution, Vol. 7). Cambridge, Mass.: MIT Press.

Binmore, K. (2010). Social norms or social preferences? Mind \& Society, 9(2), 139-157, doi:10.1007/s11299-010-0073-2.

Bratman, M. (1987). Intention, plans, and practical reason. Cambridge, Mass.: Harvard University Press.

Butler, J. (1990). Gender trouble: feminism and the subversion of identity (Thinking gender). New York: Routledge.

Camerer, C. F., \& Fehr, E. (2004). Measuring social norms and preferences using experimental games: a guide for social scientists. In J. P. Henrich (Ed.), Foundations of human sociality: economic experiments and ethnographic evidence from fifteen small-scale societies (pp. 55-95). Oxford: Oxford University Press.

Cialdini, R. B., Kallgren, C. A., \& Reno, R. R. (1991). A focus theory of normative conduct: a theoretical refinement and reevaluation of the role of norms in human behavior. Advances in experimental social psychology, 24, 201-234.

Elster, J. (1989). Nuts and bolts for the social sciences. Cambridge: Cambridge University Press.

Elster, J. (1999). Alchemies of the mind: rationality and the emotions. Cambridge: Cambridge University Press.

Elster, J. (2009). Norms. In P. Hedström, \& P. Bearman (Eds.), The Oxford handbook of analytical sociology (pp. 195-217). Oxford: Oxford University Press. 
Frankfurt, H. G. (1988). Rationality and the unthinkable. In H. G. Frankfurt (Ed.), The importance of what we care about (pp. 177-190). Cambridge: Cambridge University Press.

Garfinkel, H. (1967). Studies in Ethnomethodology. Englewood Cliffs: Prentice-Hall.

Gigerenzer, G. (2010). Moral satisficing: rethinking moral behavior as bounded rationality. Topics in cognitive science, 2(3), 528-554.

Gigerenzer, G., \& Brighton, H. (2009). Homo heuristicus: why biased minds make better inferences. Topics in cognitive science, 1(1), 107-143.

Göckeritz, S., Schmidt, M. F., \& Tomasello, M. (2014). Young children's creation and transmission of social norms. Cognitive Development, 30, 81-95.

Haslanger, S. (2015). What is a structural explanation? Philosophical Studies, doi:10.1007/s11098-014-0434-5.

Jasper, J. M. (2011). Emotions and social movements: twenty years of theory and research. Annual Review of Sociology, 37(1), 285-303, doi:10.1146/annurev-soc-081309150015.

Kahneman, D. (2011). Thinking, fast and slow. New York: Farrar, Straus and Giroux.

Klein, G. A. (1995). A recognition-primed decision (RPD) model of rapid decision making. In J. O. G. Klein, R. Calderwood, and C. E. Zsambok (Ed.), Decision making in action: models and methods (pp. 138-147). Norwood, NJ: Ablex Publishing.

Köymen, B., Lieven, E., Engemann, D. A., Rakoczy, H., Warneken, F., \& Tomasello, M. (2014). Children's norm enforcement in their interactions with peers. Child Development, 85(3), 1108-1122.

Lipshitz, R., \& Ben Shaul, O. (1997). Schemata and mental models in recognition-primed decision making. In C. E. Zsambok, \& G. Klein (Eds.), Naturalistic decision making (pp. 293-303). Mahwah: Lawrence Erlbaum Associates.

Marshall, S., \& Seel, N. M. (2012). Schemas and decision making. In N. M. Seel (Ed.), Encyclopedia of the sciences of learning (pp. 2956-2959). New York: Springer.

McAdams, R. H., \& Rasmusen, E. B. (2007). Norms and the law. In A. M. Polinsky, \& S. Shavell (Eds.), Handbook of law and economics: Vol. 2 (Vol. 2, pp. 1573-1618). North-Holland: Elsevier.

Newman, D. M. (2008). Sociology: exploring the architecture of everyday life (7th ed.). Thousand Oaks: Pine Forge Press.

Nolan, J. M., Schultz, P. W., Cialdini, R. B., Goldstein, N. J., \& Griskevicius, V. (2008). Normative Social Influence is Underdetected. Personality and Social Psychology Bulletin, 34(7), 913-923, doi:10.1177/0146167208316691.

Paternotte, C., \& Grose, J. (2013). Social norms and game theory: harmony or discord? British Journal for the Philosophy of Science, 64(3), 551-587.

Ross, K. G., Klein, G. A., Thunholm, P., Schmitt, J. F., \& Baxter, H. C. (2004). The recognition-primed decision model. Military Review, 84(4), 6-10.

Rossano, F., Rakoczy, H., \& Tomasello, M. (2011). Young children's understanding of violations of property rights. Cognition, 121(2), 219-227.

Scheff, T. J. (2006). Mobilization and silence: emotional/relational dynamics. Work. Pap., UC Santa Barbara, 
Schmidt, M. F., Rakoczy, H., \& Tomasello, M. (2011). Young children attribute normativity to novel actions without pedagogy or normative language. Developmental Science, 14(3), 530-539.

Schmidt, M. F., Rakoczy, H., \& Tomasello, M. (2012). Young children enforce social norms selectively depending on the violator's group affiliation. Cognition, 124(3), 325-333.

Searle, J. R. (1995). The construction of social reality. New York: Free Press.

Sherif, M. (1936). The psychology of social norms. New York, London: Harper.

Simon, H. A. (1956). Rational choice and the structure of the environment. Psychological Review, 63(2), 129-138.

Smith, L. G. E., Thomas, E. F., \& McGarty, C. (2014). "We must be the change we want to see in the world": integrating norms and identities through social interaction. Political Psychology, online first, doi:10.1111/pops.12180.

Wyman, E., Rakoczy, H., \& Tomasello, M. (2009). Normativity and context in young children's pretend play. Cognitive Development, 24(2), 146-155. 